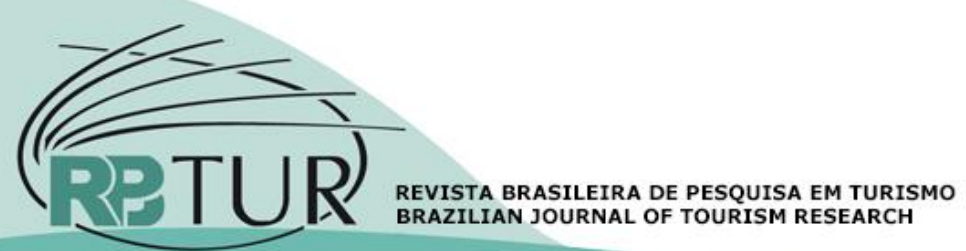

\title{
Perspectivas
}

\section{Hospitalidade, turismo e lazer}

\author{
Hospitality, tourism and leisure
}

Hospitalidad, turismo y ócio

\section{Luiz Octávio de Lima Camargo ${ }^{1}$}

1 Universidade Anhembi Morumbi/USP-EACH, São Paulo, SP, Brasil.

\begin{tabular}{|c|c|}
\hline Palavras-chave: & Resumo \\
\hline $\begin{array}{l}\text { Hospitalidade. } \\
\text { Lazer. } \\
\text { Turismo. } \\
\text { Turismo sexual. } \\
\text { Overturismo. } \\
\text { Escola. }\end{array}$ & $\begin{array}{l}\text { Este artigo trata das relações conceituais entre hospitalidade, lazer e turismo, das vanta- } \\
\text { gens heurísticas dessa articulação e das suas decorrências para os estudos nessas três } \\
\text { áreas, hoje próximas mas ainda separadas. Para tanto, após estabelecer as semelhanças e } \\
\text { diferenças entre esses conceitos, pretende mostrar como a articulação desses conceitos } \\
\text { pode enriquecer a análise dos casos hoje bastante discutidos do overturismo, da escola e } \\
\text { do turismo sexual. Finalizando, mostra que a emergência dos estudos de mobilidade e da } \\
\text { economia da felicidade tendem a contribuir ainda mais para a integração dessas áreas. } \\
\text { Abstract }\end{array}$ \\
\hline $\begin{array}{l}\text { Hospitality. } \\
\text { Leisure. } \\
\text { Tourism. } \\
\text { Sex tourism. } \\
\text { Overtourism. } \\
\text { School. }\end{array}$ & $\begin{array}{l}\text { This article examines the conceptual links between hospitality, tourism, and leisure, as well } \\
\text { as the heuristic advantages of such articulation and implications for studies in these fields, } \\
\text { today closely connected yet still distinct. To this end, after establishing the similarities and } \\
\text { differences between the concepts, I will try to show how the articulation of these concepts } \\
\text { can contribute to the current discussion of overtourism, school, and sex tourism. Finally, it is } \\
\text { discussed how the emergence of studies on mobility and the economics of happiness tend } \\
\text { to strengthen the integration of these fields. }\end{array}$ \\
\hline Palavras clave: & Resumen \\
\hline $\begin{array}{l}\text { Hospitalidad. } \\
\text { Ocio. } \\
\text { Turismo. } \\
\text { Turismo sexual. } \\
\text { Overtourism. } \\
\text { Escuela. }\end{array}$ & $\begin{array}{l}\text { Este artículo trata de las relaciones conceptuales entre hospitalidad, ocio y turismo, de las } \\
\text { ventajas heurísticas de esa articulación y de sus consecuencias para los estudios en esas } \\
\text { tres áreas, hoy próximas pero aún separadas. Así, tras establecer las similitudes y diferen- } \\
\text { cias entre estos conceptos, pretende mostrar cómo la articulación de estos conceptos pu- } \\
\text { ede enriquecer el análisis de los casos hoy bastante discutidos del overturismo, de la escu- } \\
\text { ela y del turismo sexual. Finalizando, muestra que la emergencia de los estudios de movili- } \\
\text { dad y de la economía de la felicidad tienden a contribuir aún más a la integración de esas } \\
\text { áreas. }\end{array}$ \\
\hline
\end{tabular}

Escrito por autor convidado.

Não avaliado por pares. \begin{abstract}
gens heurísticas dessa articulação e das suas decorrências para os estudos nessas três áreas, hoje próximas mas ainda separadas. Para tanto, após estabelecer as semelhanças e diferenças entre esses conceitos, pretende mostrar como a articulação desses conceitos turismo economia da felicidade tendem a contribuir ainda mais para a integração dessas áreas.
\end{abstract}

This article examines the conceptual links between hospitality, tourism, and leisure, as well as the heuristic advantages of such articulation and implications for studies in these fields, differences between the concepts, I will try to show how the articulation of these concepts can contribute to the current discussion of overtourism, school, and sex tourism. Finally, it is discussed how the emergence of studies on mobility and the economics of happiness tend Resumen tres areas, hoy proximas pero aun separadas. Así, tras establecer las similitudes y diferenede enriquecer el análisis de los casos hoy bastante discutidos del overturismo, de la escuáreas.

Como citar: Camargo, L.O.L. (2019). Hospitalidade, turismo e lazer. Revista Brasileira de Pesquisa em Turismo, São Paulo, 13 (3), p. 1 - 15, set./dez. DOI: http://dx.doi.org/10.7784/rbtur.v13i3.1749 


\section{INTRODUÇÃO}

O convite desta revista aos agraciados pela ANPTUR com a láurea de pesquisador emérito é uma dádiva que, mais do que qualquer outra, não pode ser recusada. Sempre tolhidos por normas acadêmicas cada vez mais rigorosas, obrigados que somos a permanecer nos limites estreitos da objetividade científica, a possibilidade aqui aberta de expor livremente ideias acerca dos desafios e das tendências da pesquisa em turismo certamente é um presente excepcional. Parafraseando a exclamação de meu mestre Joffre Dumazedier sobre o privilégio do doutor de expor livremente suas ideias à crítica dos colegas, eu também diria: "ça vaut de I'or!", isto vale ouro, e é um crime recusar.

A possibilidade de escrever na primeira pessoa é outro presente e, apesar da promessa de tribuna livre, suscita a questão: o que, em minha trajetória acadêmica, justifica uma reflexão relevante para os colegas? $\mathrm{Na}$ qualidade de decano dos pesquisadores de lazer no país, de introdutor e coordenador de cursos de turismo e hotelaria e de participante de primeira hora na criação do Programa de Pós-graduação em Hospitalidade da Universidade Anhembi Morumbi, decidi que minha contribuição deveria ser uma tentativa de aproximação teórica das três áreas, através da resposta à seguinte questão: quais são as relações entre lazer, turismo e hospitalidade? Ou, em outros termos: o que e em que a minha experiência acadêmica nas três áreas pode trazer de relevante aos colegas?

Recorde-se que estas áreas de estudo estão articuladas e ora a âncora é a hospitalidade, ora o turismo, ora o lazer. 0 pressuposto deste artigo é que a correlação desses conceitos pode ser benéfica para cada uma delas e certamente enriquecerá as análises que lançarem mão deles conjuntamente.

Por isso, pareceu-me que não bastava ater-me ao plano epistemológico, de aproximação de teorias. Decidi, então, ilustrar esta reflexão teórica com exemplos em que a articulação dessas noções mostrasse poder heurístico, de suscitar novas abordagens. Este segundo desafio, da escolha de exemplos, mostrou-se mais difícil!

Lazer e turismo têm em comum diversas propriedades e a mais significativa, ao menos a mais evidente, é a busca de ludicidade. Como disse Maffesoli (2005), as sociedades ocidentais acabam de deixar dois séculos vivendo à sombra de Prometeu - o deus do trabalho que teve o destino de viver eternamente acorrentado a um rochedo no qual as águias vinham comer-lhe o fígado durante o dia, deixando que a noite regenerasse $o$ órgão para o dia seguinte. Este mito pode ser facilmente lido como o destino do trabalhador surgido da revolução industrial, condenado ao duro labor cotidiano e tendo o descanso apenas como instância reparadora das forças. A episteme, conceito que ele importa de Foucault (1999), o espírito do tempo, o paradigma era do dever, da obrigação. Contudo, continua Maffesoli, desde a metade do século XX, vivemos à sombra de Dioniso, o deus do sexo e das drogas, e a nova episteme é a busca do prazer no cotidiano da vida familiar, do trabalho, do rito religioso. Nessa narrativa, o lazer e o turismo, espaços já constituídos tendo o hedonismo como uma de suas propriedades, têm essa busca do prazer ainda mais acentuada. Um bom exemplo são as iniciativas de reformulação de espaços de lazer em geral tendo como lógica a busca de uma espécie de sobreprazer. Outro exemplo, que trazemos aqui e que pode proporcionar uma boa ilustração da articulação desses conceitos é o do turismo sexual. A noção de hospitalidade teria algo a acrescentar?

Turismo e hospitalidade por sua vez enfrentam o problema do momento, o do overturismo, da superlotação de locais de interesse dos turistas. Desde a emergência do turismo de massa após os anos 1950, as cidades são ávidas dos recursos dos turistas mas tanto estes como os moradores locais revoltam-se contra todos os excessos decorrentes: de gente, de barulho, de congestionamentos, de alta dos preços. Esses problemas já existem há muito tempo e deram origem aos estudos de impactos negativos do turismo desde os anos 1970. Ocorre que o problema agora chega ao que se pode chamar de limite, de situação insustentável, que traz à tona a turismofobia. Os legisladores, os promotores e os pesquisadores de turismo estão atrás de respostas. Teriam a hospitalidade e o lazer algo a acrescentar?

A escola não é objeto prioritário de estudo em nenhuma dessas três áreas. Pode-se mesmo dizer que, ao estabelecer-se sob a égide da disciplina, tende a colocar-se no plano oposto ao do prazer que está na base da procura do lazer e do turismo. Assim sendo, torna-se excludente de todos os que de alguma forma não se ajeitam dentro do padrão imposto da disciplina. Se é através da escola que a sociedade acolhe seus novos membros, teria ela o direito de propor uma escola excludente de todos os que não sintonizam com a 
disciplina proposta? Esta questão traz a escola como um problema da hospitalidade do lazer e também do turismo.

No desenvolvimento desta reflexão, será mantida, do rol de praxes acadêmicas, apenas as referências às fontes. Imagino que algumas reflexões sejam ousadas e, se bem aceitas, devem ser creditadas à revista; caso contrário, que sejam colocadas no rol de reflexões destemperadas de um pesquisador perto da aposentadoria e que não perde o púlpito que lhe é oferecido.

\section{RELAÇÕES ENTRE HOSPITALIDADE E TURISMO: O CASO DO OVERTURISMO}

Como os estudos turísticos impactam nos estudos de hospitalidade e vice-versa? Comecemos pelo mais simples, pela contribuição dos estudos de turismo para a hospitalidade. Por mais banal que possa parecer a observação, o turismo teve de se fazer ouvir nos estudos de hospitalidade, marcados que foram pela pressão de outro tipo de migração, a que leva pessoas de regiões pobres ou marcadas por conflito na direção de regiões e países mais ricos. É importante lembrar que não é por acaso que Levinas (1988), Derrida (Dufourmantelle, 2003), Buber (2001), Montandon (2011), Gotman (2009), Shérer (2004) e os estudiosos francófonos pensam a hospitalidade como um problema do migrante. É verdade que esta situação de populações pobres buscando lugares que podem Ihes proporcionar condições dignas de vida (mormente agora no caso dos refugiados) fala mais à sensibilidade social do pesquisador do que a migração turística, mormente de turistas de regiões ricas que se deslocam para desfrutar de regiões pobres.

Ocorre que também as migrações turísticas são palco de conflitos, tanto dos turistas que não raro tratam as populações do país visitado como conquistadores em terra arrasada, como dos moradores locais que veem no turista um objeto de exploração econômica. A expressão "isto é para turista", que pode ser traduzida como "isto é caro e fake", desvela toda a antipatia suscitada pelo visitante, além de reduzir o turista à figura de um simples idiota que não sabe o que fazer com seu dinheiro.

Nos países anglófonos, diferentemente dos francófonos, o turismo foi a porta de entrada dos estudos de hospitalidade, o que aconteceu inclusive por uma particularidade linguística: hospitality designa simplesmente as áreas de hotelaria e eventos. Com isso, a hospitalidade abriu-se automaticamente aos estudos turísticos, ainda que designando apenas o receptivo turístico. Somente nos últimos anos é que o grupo britânico coordenado por Lashley e Morrison (2005) resgatou a amplitude socioantropológica do termo. Assim, inversamente, lá este estudo começou pelo turismo e agora, com Lugosi (Lugosi \& Allis, 2019), chega aos migrantes que não deixam suas origens por simples desejo de uma nova vida, mas como refugiados, como expulsos de suas terras.

De qualquer forma, hoje, ouve-se muito hoje falar em hospitalidade dentro do turismo, parecendo mesmo a alguns até que são sinônimos. É óbvio que, dentro do turismo, sempre acontece algum tipo de hospitalidade. É impossível conceber uma viagem (exceto no vaso dos desbravadores de regiões inóspitas ou que buscam testar limites) sem alguém que viaja e alguém que acolhe, por mais que esse alguém que acolhe seja o chamado receptivo turístico ou, na fórmula humanizada de Márcia Cappellano dos Santos e Perazzolo (2012), o corpo coletivo acolhedor.

Num mundo cada vez mais globalizado e numa cultura cada vez mais mundializada, conjuntura assentada como lembram Panosso Netto e Trigo (2009) em três pés - o mercado financeiro, a mídia e o turismo - a associação conceitual entre hospitalidade e turismo é cada vez mais forte.

Podemos definir hospitalidade, do ponto de vista analítico e operacional, como um processo de interação humana em contexto doméstico, urbano, comercial e virtual, dentro do qual um anfitrião recebe, eventualmente ainda hospedando, e/ou alimentando e/ou entretendo, um visitante/hóspede temporariamente deslocado de seu "habitat" natural.

Esta definição é quase uma reprodução da noção de turismo da Organização Mundial do Turismo (World Tourism Organization): "é a atividade do viajante que visita uma localidade fora de seu entorno habitual, por período inferior a um ano, e com propósito principal diferente do exercício de atividade remunerada por entidades do local visitado". 
Infere-se automaticamente que a primeira contribuição da noção de hospitalidade para o turismo é mostrar que o estudo do encontro turístico pode ser alargado se o entendermos no contexto dos encontros interpessoais em geral. A noção de encontro turístico traz embutida a ideia de encontro com o estranho (todo estranho não é uma espécie de estrangeiro?) assim entendido o vizinho que não conhecemos, o indivíduo que nos para na rua (ou que nós paramos) para confirmar um endereço, o novo colega de trabalho, o recepcionista do hotel de um país que visitamos, o esquimó cuja aldeia visitamos.

A noção de hospitalidade alarga esse desafio assumindo a missão declarada do turismo, de contribuir para a paz universal mostrando que, se não criamos laços com o pouco estranho, como fazê-lo com o muito estranho?

A matriz da noção de hospitalidade é o encontro com o outro (sempre estranho) que acontece na casa. A partir daí, contamina os modelos de encontro que acontecem em diferentes instâncias da vida social, corrigindo uma ideia errônea de uma ruptura entre os modelos de hospitalidade que acontecem no espaço doméstico, urbano, comercial e virtual. Somos anfitriões quando estamos em nossa casa e, quando interagimos com outras pessoas (parentes, vizinhos, bem como pessoas conhecidas e estranhos que nos procuram), ou quando, fora de casa, nos locais de trabalho, interagimos com os que procuram a empresa. Somos hóspedes, sempre que saímos de casa e buscamos a hospitalidade de escolas, hospitais, clínicas, repartições públicas, parques, centros comerciais, bancos, bares, restaurantes, dentro da nossa cidade. As pessoas que ali trabalham, nossos anfitriões, nos devem o bem receber e, eventualmente, o bem alimentar e entreter. Sob o prisma da hospitalidade, são condenáveis todas as práticas dos nossos anfitriões que nos condenam a longas filas, momentos tediosos, sem falar das grosserias e intimidações.

Esta ideia é importante para um ator do receptivo turístico, o hotel. O hotel não é anfitrião. É impessoal. São as pessoas que lá trabalham os verdadeiros anfitriões. Estes trazem a chamada cor local, na postura, nos gestos, nas palavras, etc. As grandes redes e cadeias hoteleiras e de restaurantes imaginam, às vezes, estilos de hospitalidade artificiais, padronizados por necessidade administrativa e às vezes até mesmo em nome da qualidade. Tudo se passa como se a recepção de um hotel ou restaurante ganhasse em qualidade se uniformizadas independentemente das características socioculturais e econômicas dos diferentes territórios nos quais se processa. Isso é um problema. Se não concebermos uma cor, um estilo local de receber, teremos uma hospitalidade asséptica, sem cor, cheiro e tonalidade locais e, certamente, o "nãolugar", que provoca no hóspede a sensação de estar numa espécie de limbo, de passagem, ou lugar nenhum (Augé, 1994) e certamente também tem algo a ver com o falso evento, o evento pelo evento, ou como Boorstin (1964) denominou e estudou, o pseudo-evento.

O hotel urbano não é uma destinação, como o resort, mas infraestrutura turística. 0 turista visita a cidade e não o hotel e não há porque ele volte voluntariamente ao hotel se não gostou da cidade. Um bom hotel numa cidade inospitaleira somente pode ser viável na hospitalidade de negócios, quando a viagem não é discricionária. Não são poucos, aliás, os que preveem que, com a evolução da hospitalidade no domínio virtual, mesmo as viagens de negócios sempre serão pontuadas e perpassadas por interesses de lazer e, neste caso, as cidades inospitaleiras serão as grandes perdedoras.

O entendimento de que o receptivo turístico envolve a cidade e toda a população local, o que torna todos os seus habitantes igualmente responsáveis pelo êxito do acolhimento, eis uma lição da sociologia do hotel e a segunda contribuição da hospitalidade para o turismo.

A terceira contribuição é decorrente e pode ser assim resumida: os estudos turísticos confrontam um público emissor (os turistas) e um receptivo turístico composto de postos de informação, hotel, centro de eventos, restaurantes, comércio. A população residente como um todo não é reconhecida e, com justa razão, protesta contra o fato de grandes eventos e o turismo como um todo beneficiarem apenas esse receptivo (o trade local) ficando a população com o aumento dos preços, o congestionamento, a prostituição, a violência. A hospitalidade, como dito acima, ocupa-se de pessoas. Confronta e pretende articular o conjunto de visitantes com os moradores locais. Valoriza a democratização dos benefícios inclusive econômicos do turismo e procura ajustar acessibilidade, regulamentação do acesso e convivência com o turista.

Lembre-se também, que, se, no início, os estudos turísticos eram marcadamente econômicos e resumiamse na tríade turista-transporte-hotel, aos poucos essa visão começou a alargar-se para o estudo do visitado. 
Na década de 1970, Valene Smith (1977) e seu grupo inauguram a antropologia do turismo, colocando em relevo a figura do morador local, mas a própria noção de impacto turístico já deixa entrever que o foco continua assentado no visitante e nas marcas positivas e negativas que este deixa sobre o solo e a população visitados. Mas como fica o estudo do impacto do visitado sobre o visitante? É tratado sob a denominação de expressões como "olhar turístico" "experiência turística". Em outros termos: mesmo nas abordagens do grupo de Valene Smith o residente continua passivo.

Se a abordagem desse grupo já aproximava as noções de hospitalidade e turismo, a Organização Internacional de Turismo Social-OITS (antigo Bureau International de Tourisme Social-BITS) deu um passo à frente. Sua marca sempre foi o resgate integral da experiência turística da viagem, tendo como ponto alto a integração com as comunidades locais. Não obstante a importância das organizações abrigadas nessa marca, o turismo social sempre foi tratado marginalmente nos estudos turísticos, vulgarmente associado ao turismo de pobres. No Brasil, restou o prestígio de um dos principais autores ligados à OITS, Jost Kryppendorf (1989) e as três fórmulas que ele traz nas suas recomendações finais insólitas de seu livro (viaje para lugares cada vez mais próximos, viaje sempre para o mesmo lugar, não saia de casa) bem como o trabalho que temos para explicar aos alunos que ele não é inimigo do turismo.

Mais recentemente, a noção de turismo sustentável também segue a trilha do cuidado com os residentes, mas deve-se notar em todas essas iniciativas que o foco continua sendo o viajante. Já noção de hospitalidade, mesmo no senso comum, faz o caminho contrário, atribuindo o protagonismo ao visitado e nenhum papel é reservado ao visitante. Vejam-se, por exemplo, as definições dos dicionários, tanto de língua portuguesa ${ }^{1}$ como francesa ${ }^{2}$ e inglesa ${ }^{3}$.

Na verdade, a noção de hospitalidade desvela uma interação complexa entre um anfitrião e um hóspede, tratando a ambos como atores de importância igual para o bom encaminhamento da cena hospitaleira. Esta é a terceira contribuição da noção de hospitalidade para o estudo do turismo e hoje essa colaboração entre as áreas é essencial quando nos defrontamos com um assunto complexo como o overturismo, de que passamos a tratar agora.

Como lembra Goodwin (2017), o overturismo descreve uma situação em que o excesso de visitantes traz para turistas a sensação de que a qualidade da experiência se deteriorou e para os locais a sensação de deterioração da qualidade da vida cotidiana. É o oposto do turismo responsável. Como lembra esse autor, o fenômeno decorre de fatores variados: do lado do turista, o custo cada vez menor das viagens, a desintermediação da hospedagem com as novas plataformas, o gosto dos ricos e da nova classe média por viajar. Do lado dos residentes, o desarranjo do mercado imobiliário, o aumento do custo de vida, o incômodo da superlotação dos espaços, do burburinho humano, o fato de visitantes nada pagarem pelo impacto na paisagem cuja manutenção fica a cargo dos moradores, o fato de os empregos gerados pelo setor continuarem sendo sazonais e mal remunerados. Daí que expressões como turismofobia e similares começam a ganhar a mídia e o fenômeno entra em círculo vicioso: mais se fala dos problemas de superlotação dos lugares visitados e dos incômodos sofridos pelos locais mais se aumenta o interesse dos turistas e mais aumenta o desconforto dos locais. Ademais, o overturismo surge numa hibridação da figura do turista hospedado, que gasta, e o excursionista/visitante do dia, que nada gasta, como acontece com as hordas que os cruzeiros despejam diariamente. Com isso, as sociedades visitadas começam a elaborar medidas de proteção que certamente devem alterar o estatuto do turismo nessas regiões.

A World Tourism Organization (2019) listou as seguintes estratégias que estão sendo desenvolvidas nos principais centros receptores vitimados pelo overturismo:

1. Promover a dispersão de visitantes dentro da cidade e arredores;

2. Promover a dispersão baseada em tempo dos visitantes;

\footnotetext{
1 "Ato de hospedar; hospedagem." (Dic. Aurélio, Rio. Nova Fronteira, 1986) ou "1. Bom acolhimento dispensado a alguém. 2.Agasalho dado a hóspedes. (Dicionário Michaelis, 1998).

2 "Action de recevoir et d’héberger quelqu un chez soi, par charité, liberalité, amitié" (Le Petit Larousse, Paris, 1993).

3 "The food, drink and other conforts that a organisation sometimes provides in order to keep its guests happy (Cambridge International Dictionary of English, Londres, 1995) ou 1. Welcoming behavior toward guests. 2. Food, a play to sleep, etc. when given to a guest (Longman Dictionary of English Language and Culture, Londres, 1992).
} 
3. Estimular novos itinerários e atrações dos visitantes;

4. Rever e adaptar a regulamentação;

5. Melhorar a segmentação dos visitantes;

6. Garantir que as comunidades locais se beneficiem do turismo;

7. Criar experiências urbanas que beneficiem tanto moradores e visitantes;

8. Melhorar a infraestrutura e as instalações da cidade;

9. Comunicar-se com e envolver a os stakeholders locais

10. Comunicar-se com e envolver os visitantes; e

11. Definir medidas de monitoramento e resposta.

Note-se que das 11 estratégias listadas pela OMT, duas ( 6 e 8) dizem respeito exclusivamente aos benefícios aos moradores e três (7, 9 e 10) falam da interação entre visitantes e visitados. Mais uma evidência da aproximação dos conceitos turismo e hospitalidade.

Em que, assim, a noção de hospitalidade pode trazer alguma luz adicional para o problema? Apelar para a noção de hospitalidade implica em trazer o problema do plano político para o plano ético e este, quem sabe, pode iluminar o problema político. Este plano político é o das leis escritas: direito de aduana, direito comercial. O plano ético é basicamente o das leis não-escritas. Sua pergunta é: em que se baseia o direito dos turistas de conhecer os locais e o direito dos residentes de impor obstáculos à sua presença? 0 que a hospitalidade tem a dizer aos dois grupos?

A princípio, a consigna é clara: a hospitalidade incondicional exige que o visitante (hóspede) seja acolhido em quaisquer circunstâncias, mas o morador local (anfitrião), mesmo tendo o dever de acolhê-lo, tem em contrapartida o direito de impor regras inclusive para o uso do espaço. Mas esse residente é o mesmo anfitrião que recebe alguém na casa que construiu e comprou? De forma insólita, a perspectiva da hospitalidade pode desta vez favorecer ao hóspede, o turista.

Ficando no exemplo de Veneza: entende-se o direito dos residentes, mas deve-se também constatar que o morador atual nada contribuiu para a implantação das riquezas culturais da cidade e certamente pouco as aproveita. Ademais, o morador local, como todo residente, vive mergulhado nas suas ocupações cotidianas e pouco deve desfrutar da paisagem e dos atrativos. Tomando o exemplo do Rio de Janeiro, pesquisa de 1975 (Medina, 1976) já mostrava que mais da metade da população simplesmente não saía de casa nos fins de semana e, entre as donas de casa, o percentual passava dos 70\%. Na mesma época, um estudo de orçamento-tempo (Souza, 1976) mostrava que o tempo semanal de praia dos cariocas não passava de 7 minutos, o que significava frequência muito limitada.

Isto não seria um problema se bilhões de pessoas não tivessem interesse em apenas ter o privilégio de olhar para as paisagens de Veneza e Rio de Janeiro por um dia que seja! De que forma, esse morador local pode alegar que a paisagem natural, bem como a arquitetônica produzida por gerações e gerações, é uma propriedade parecida com a casa que construiu ou a tem alugada?

Por outro lado, o turista também não é um hóspede convencional. Em primeiro lugar, para ele, existe o que Miguel (2016) chama de "direito de conhecer o mundo e de adquirir os instrumentos para pensar com a própria cabeça" e que, conforme Gotman (2009) sempre foi reivindicado pelos antropólogos para justificar sua intrusão em territórios indígenas. Em segundo lugar, o site da cidade o convida e diz que ele é bem vindo, ainda que o convite pareça vir temperado dos problemas ligados ao excesso de visitação: "visite e respeite Veneza", diz o site. Esse turista é o mesmo indivíduo que eu convido para jantar em minha casa e chamo de hóspede? Qual é a retribuição à hospitalidade recebida?

Veneza, tal como a maioria dos ambientes vítimas do overturismo, está no rol de territórios consagrados pela UNESCO como "patrimônio da humanidade" e, como tal, faz parte de um "legado de monumentos e locais de grande riqueza natural e cultural que pertencem a toda a humanidade (e) cumprem uma função de marcos do planeta, de símbolos da consciência de Estados e povos sobre o significado desses lugares e 
emblemas de seu apego à propriedade coletiva, bem como da transmissão desse patrimônio para as gerações futuras".

Com isso, a hospitalidade convida para pensar em outra questão: como conciliar interesses de uma população ansiosa por desfrutar momentos mesmo que fugazes das riquezas de uma localidade relativamente desdenhadas pela população residente?

É evidente que as políticas têm de caminhar para uma solução racional do problema, exigindo dos visitantes, sem negar-Ihes o direito à visita, vantagens que permitam aos moradores locais sentirem-se compensados pelos transtornos provocados pelo burburinho a que são submetidos. Isso poderia ser até o embrião de uma política realmente de turismo, de incentivo à viagem para os moradores locais, já que as atuais políticas, voltadas à atração de visitantes, deveriam chamar-se mais adequadamente de políticas de hospitalidade. Da mesma forma como os moradores mais ricos de Paris viajam para outros locais para fugir do excesso de visitantes durante a alta temporada, quem sabe uma política de turismo utilizando recursos dos visitantes possa incentivar os moradores locais mais incomodados a viajar para conhecer riquezas de outras localidades!

\section{RELAÇÕES ENTRE HOSPITALIDADE E LAZER: O CASO DA ESCOLA}

As relações entre hospitalidade e lazer são bem mais sutis. Receber alguém é ocupar-se dele e além do acolhimento há a tarefa de alimentar e entreter o hóspede, além de eventualmente hospedar. Essa necessidade de entreter o hóspede faz da habilidade na conversação (ao lado da oferta de alimento e, sobretudo, de bebida) um grande instrumento ao mesmo tempo do lazer e da hospitalidade. Ser um causeur, alguém dotado da qualidade da conversação, da capacidade de "segurar" uma conversa faz dele alguém competente tanto enquanto anfitrião como enquanto hóspede, alguém dotado daquilo que os britânicos chamaram de "hospitabilidade", de qualidade hospitaleira.

Este termo merece um reparo importante para a compreensão da hospitalidade. Para os anglófonos em geral, hospitality, como lembrado acima, converteu-se em substantivo que designa o setor econômico do acolhimento comercial, basicamente hotelaria e eventos e não a qualidade de um indivíduo hospitable, que se porta bem na cena hospitaleira. Para designar a qualidade do indivíduo hospitable existe o hospitableness (condição de hospitalidade) ou hospitability (capacidade de hospitalidade). Em português, aparentemente não há tal necessidade, já que o substantivo hospitalidade designa a qualidade correspondente.

Mas esse significado não é unívoco. Em português, também, o substantivo hospitalidade designa um setor comercial e, portanto, pode ter uma conotação positiva como negativa. Quando se diz que uma cidade tem problema de hospitalidade quer-se dizer que o seu setor receptivo tem problemas: nos terminais de transporte, na sinalização, na hotelaria, etc. Isso justifica a adoção do anglicismo "hospitabilidade" também para nós, com o mesmo significado de capacidade de hospitalidade.

Já quanto à hospitalidade vista a partir dos estudos do lazer, importa mostrar que, segundo as pesquisas de orçamento-tempo (Souza, 1976), a maior parte do tempo de lazer é consumida dentro de casa e dividida quase que igualmente entre o acesso à mídia e a hospitalidade doméstica. Existe mesmo uma estranha uniformidade nos resultados das pesquisas de orçamento-tempo: não importa o tamanho das cidades, seu clima, seus atrativos, sua localização dentro do globo terrestre, aproximadamente $70 \%$ do tempo de lazer é consumido dentro de casa e dois tipos de atividade dividem esse tempo: de um lado, isso que chamamos de hospitalidade doméstica (vida em família, visitar e receber amigos, eventos diversos, cuidados com a decoração, pequenos reparos, com os animais e plantas, diário íntimo) e de outro, o acesso à mídia em sentido amplo (rádio, tevê, internet, redes sociais, e-mail, cartas).

Esta uniformidade de resultados é uma evidência de que a casa tem outros significados para o indivíduo além do sociológico ou demográfico, remetendo o indivíduo à sua própria identidade. Nos contos de fada, tão presentes no nosso imaginário, perder-se é não saber o caminho de volta para casa. Para os psicoterapeutas, sonhar com casa remete ao que os existencialistas alemães, como Biswanger, à eigenwelt, à relação do indivíduo consigo mesmo. Aquele que, em outra cidade, já ficou, ainda que momentaneamente, sem 
endereço (casa ou hotel) conhece uma sensação de estranhamento que certamente não tem a ver com o simples desconforto com o depósito de bagagens.

Daqui vem outra questão: estaria em declínio, como pensa o senso comum, a hospitalidade no espaço doméstico? É verdade que, hoje, menos pessoas são introduzidas no ambiente familiar, menos se conhecem os vizinhos, menos aberta é a casa para amigos e conhecidos, mais é esperada a formalidade no trato com estranhos. Na verdade, essa hospitalidade é regrada por leis marcadas pela insegurança e por aquela lei deduzida da urbanidade (cuidado com estranhos): é um fenômeno que se acentua na proporção direta do tamanho da população, sendo bastante visível nas metrópoles. Essa percepção, contudo, deve ser no mínimo contrabalançada com outra: se é menor o número de convidados e hóspedes, maiores são os cuidados dos anfitriões para com eles. A figura do hóspede casual praticamente inexiste nas grandes cidades. Por isso, o próprio convite para uma visita já é um primeiro passo, senão em direção à amizade, ao menos de aceitação do outro.

A hospitalidade em espaço doméstico continua sendo tão importante que há uma infinidade de programas de tevê destinados exclusivamente ao viver em casa e que tem como justificativa básica o receber (vizinhos, parentes, amigos, colegas de trabalho): arquitetura, decoração, mobiliário, economia doméstica, organização do espaço, etc. Em resumo: receber bem deixa de ser um gesto informal e entra nas regras do bem viver.

Uma segunda relação da hospitalidade com o lazer diz respeito aos espaços. 0 dever do anfitrião de entreter seu hóspede mergulha o pesquisador na problemática do lazer urbano e na necessidade especial para organizações e equipamentos de lazer, como lembra Jean Viard (2005), de se ocuparem da hospitalidade dos lugares. Diferentemente do que ocorre nos espaços profissionais e de ensino, nos quais a disciplina pessoal e a hierarquia regem as relações, os espaços de lazer chamam outra espécie de relações, marcadas pela afinidade pessoal e pela ludicidade. São também espaços educacionais, dentro da chamada educação nãoformal e, como tal, regidos por uma pedagogia de diretrizes opostas às da escola e da educação formal: ao invés do autoritarismo a persuasão; ao invés da repressão, a dissuasão. Ao invés do "deve" o "por que não?" e ao invés do "não" o "e se".

As instituições de educação não-formal - centros culturais, centros esportivos, museus, bibliotecas públicas - dependem, para conseguir clientes, da adesão destes às suas propostas e atividades. Necessitam de um desenho arquitetônico convidativo, de uma recepção acolhedora, de integração das instalações para favorecer a participação no maior número de atividades, de polivalência cultural (para permitir com facilidade a variedade e/ou substituição de atividades) e social (para permitir convivência de públicos diferentes), de pessoal hospitaleiro ao menos pela necessidade da presença do outro, de uma vigilância discreta e sem a truculência comum em equipamentos de outras áreas, como bancos, shoppings e mesmo a escola.

E é exatamente o insólito tema da escola que trazemos aqui para ilustrar as relações entre hospitalidade e lazer, além é claro, do turismo.

Pelo que foi dito mais acima, a escolha da escola para discorrer sobre as relações entre turismo, hospitalidade e lazer merece uma explicação preliminar, ou melhor, uma contextualização histórica.

Curiosamente, a evidência (e é uma evidência) de que a democratização das condições de participação na sociedade passa por um ensino fundamental de qualidade e universal ainda não conseguiu sensibilizar a sociedade como um todo, nem mesmo com outra evidência (e é uma evidência também) de que essa iniciativa é condição indispensável ao desenvolvimento econômico do país. Até hoje esse discurso apenas produziu o aumento de tempo em sala de aula e de dias letivos.

Recuemos até a década de 1950, quando os relatórios da Comissão Econômica para a América LatinaCEPAL (1963) já diziam que o modelo de vivência do tempo pelos migrantes do interior do nosso país era incompatível com as necessidades da indústria. Esse diagnóstico explica retrospectivamente porque, conforme Bastos (2004), a maioria dos operários em São Paulo no início do século XX eram italianos natos. 
Mesmo quando provenientes de zonas rurais daquele país, tinham um nível de cultura material e de cultura urbana suficientes para o trabalho na indústria.

Outros diagnósticos sociológicos confirmavam este cenário. Já se sabia, na época, conforme mostrado por Antônio Cândido (1964) que grande parcela dos moradores do interior do país vivia afastada da civilização, com um nível de cultura material próximo do existente no neolítico, ou seja, ainda vivia na pré-história. Sérgio Buarque de Holanda (1989), em 1936 já tinha notado que os ibéricos portugueses e espanhóis que adentraram pelo interior do país, ao invés de elevarem o nível de cultura material de escravos negros e indígenas acharam mais fácil aderir aos seus costumes. Em decorrência, o primeiro movimento de êxodo do interior para as grandes cidades, ao final do século XIX, já denotava que a infraestrutura da urbanização do país, como a chamou Flusser (1998), estava sendo constituída de indivíduos completamente despreparados para as necessidades culturais, sociais e econômicas das cidades. A desesperadora situação das moradias de periferias, verdadeiros cânceres urbanos (como no câncer físico, tratam-se de modelos de reprodução que não obedecem ao princípio orientador do coletivo das cidades), a poluição de rios com lixo, a dificuldade de lidar com os códigos urbanos, as dificuldades de preparação de mão-de-obra e a própria violência tem a ver com o despreparo de uma população rural que emigrou para as cidades, sem preparo prévio. Segundo Norbert Elias, foi nessa condição que surgiu na Europa, no alvorecer da Modernidade, o processo civilizador que, em termos simples, era um conjunto de regras para tornar o migrante mais familiarizado com a vida urbana.

Tudo isso se sabia na década de 1950, mas o remédio aplicado para compensar o atraso do interior foi ... a construção de Brasília. Se é verdade que essa medida trouxe algum impacto positivo do ponto de vista econômico, trouxe, em contrapartida, a diminuição de recursos para outras áreas, sobretudo para a escola pública, a verdadeira solução do problema para pensadores como Anísio Teixeira e Darcy Ribeiro.

Até hoje existe uma nostalgia da escola pública que nessa época começou a entrar em decadência num modelo corriqueiro entre nós, e que foi também aplicado em outras áreas, como a saúde, a segurança e mesmo a universidade: democratizar reduzindo a qualidade, ou seja, nivelamento por baixo. Leonel Brizola foi, talvez, o único político que tinha a escola pública como âncora de programa de governo. Foi com ele que Darcy Ribeiro pode resgatar o sonho, já velho de 30 anos, de universalização da escola pública de tempo integral, com os CIEPs, um modelo de escola que não se resumia às salas de aula, com amplos espaços de lazer. A lógica da disciplina cedia ao atendimento dos diferentes interesses culturais lúdicos das crianças.

0 que o estudo da hospitalidade tem a dizer sobre o assunto? Se o parto marca o acolhimento da criança pela família, a escola marca o acolhimento da criança pela sociedade. A ela cabe a formação do cidadão, é o que diz a premissa repetida à exaustação por pedagogos e estudiosos. Ora, esta escola assentada apenas na formação intelectual, com conteúdos distantes do cotidiano da criança, pode dar conta de missão tão complexa?

Para a maioria das pessoas, educação é sinônimo de escola e escola é sinônimo de sala de aula. Mas o que é uma aula escolar tradicional, normalmente expositiva, senão o processo em que o professor responde a perguntas que os alunos não fizeram e que repousam num conteúdo cujas necessidade e utilidade são mais que discutíveis? Bernard Charlot (1999), um dos poucos sociólogos a estudar a escola do ponto de vista do aluno, mostra, como resultado de suas pesquisas, que a atual escola só é hospitaleira para um quarto das crianças (um quarto delas não aceita e se evade, enquanto a metade apenas cria estratégias para sobreviver e conseguir o seu cartão de visitas, o diploma).

É importante começar pela evidência de que, desde a revolução copernicana da educação e seu princípio básico de que o sujeito da educação é o educando e não o professor ou a escola, a diretriz disciplinar que sempre orientou a escola desde os jesuítas e a Rerum Studiorum é cada vez mais substituída pela motivação lúdica. Como tornar a escola prazerosa? Os modernos métodos de pedagogia ativa não trazem embutida a ideia de que despertar o interesse lúdico de aprendizagem do aluno, a curiosidade e a ludicidade que a acompanha? Como ensinar ludicamente a matemática? Como, através de jogos, estimular o estudo da geografia (jogos como o War) ou mesmo o aprendizado de línguas? 
Não restam dúvidas de que a escola mais lúdica será também mais hospitaleira: ao invés do posicionamento artificial das crianças nas salas (por tamanho) permitirá que as afinidades pessoais se manifestem, mais movimento ao invés da tortura (que um dia ainda será denunciada) de mantê-las sentadas e quietas durante horas! 0 barulho dos recreios, que pode chegar a 100 decibéis (o máximo suportável pelo ouvido humano é de 65 decibéis), certamente é a reação natural de crianças momentaneamente livres dessas torturas.

Mas a hospitalidade e o lazer podem fazer muito mais pela escola, se esta quiser ir além da cultura intelectual média necessária ao cidadão a que ela se propõe como meta hoje. Há um formato da escola já conhecido há muito tempo e poucas são as sociedades que se dispuseram a implantá-la devido ao seu custo: é a escola de tempo integral, obrigatória e acessível a todas as crianças de 6 aos 15 anos de idade. Joffre Dumazedier, o criador da sociologia do lazer, não chegou a escrever sobre esta proposta mas frequentemente a citava em suas palestras e encontros: uma escola com 9 horas diárias de duração, divididas em 3 tempos iguais: (a) o da cultura intelectual média (a escola atual mas com tempo reduzido, coordenada pela direção com participação de professores e alunos), (b) o das atividades obrigatórias mas optativas, coordenada pelos professores com a participação da direção e dos alunos, dentro de um amplo leque de alternativas, desde o aprofundamento intelectual (certamente do interesse de alguns alunos), às atividades artísticas (teatro, cinema, música, artes plásticas) e às atividades físicas (ginástica e esportes), e (c) tempo livre com atividades coordenadas pelos alunos organizados em instituições (grêmios, clubes), com apoio dos professores e da direção.

Em outras palavras, se quiser ser hospitaleira para a totalidade das crianças, a escola precisa dar conta da totalidade de interesses culturais das crianças, não apenas intelectuais, mas também físicos, artísticos e sociais, nos quais a ludicidade é percebida naturalmente, se e quando livremente escolhidas.

É evidente que a implantação desse conceito em escala nacional hoje teria um custo imenso e dificilmente convence políticos que não olham o futuro mas simplesmente os quatro anos de mandato. Essa escola certamente terá o dobro de docentes em relação aos atuais e, idealmente, necessita de um espaço bastante diferente em relação à escola atual, tendo além das salas de aula, biblioteca e auditório, equipamentos físicos e artísticos variados. Era a grosso modo o CIEP de Brizola e Darcy Ribeiro. Um custo enorme caso se queira implantar esse modelo em todo o território nacional. Mas, ao menos de início, talvez seja necessário apelar para um conceito que está na prateleira das utopias mas que já vem dando certo em muitas cidades do nordeste do país.

O crescente movimento de intercambistas, o estudo do meio (turismo pedagógico), o incremento de programas de estudo no exterior mostra que o turismo assume na sua relação com a escola o estatuto de condição importante para a sobrevivência profissional no futuro e tende a se tornar um direito.

Na década de 1930, Bachelard (1996) escreveu sobre a verdadeira posição da escola na sociedade. Ele termina uma de suas obras mais prestigiadas com a afirmação da necessidade de inversão das necessidades sociais: a escola não foi feita para a sociedade, a sociedade é que foi feita para a escola. A escola de que ele falava não era um simples edifício muito menos o reduto de uma classe de trabalhadores. Era a sociedade como um todo. Pela primeira vez alguém enunciava o conceito que mais tarde seria chamado de sociedade educativa. Como entender, perguntava ele, os depauperados laboratórios de física, química e biologia das escolas se mesmo nas menores cidades há uma usina de geração de energia elétrica, um setor de tratamento de água, hospitais, uma série de locais enfim onde se conhece e se pratica a ciência mais atualizada?

Esse raciocínio pode ser bem estendido para outras áreas. Todas as cidades tem quadras esportivas, piscinas, auditórios, sem falar de conhecedores da cultura tradicional, artistas plásticos, músicos, todos subutilizados e subaproveitados. Por que a escola não pode aproveitá-los? Os clubes recreativos, sempre mais bem dotados de instalações do que as escolas, têm instalações ociosas a maior parte do tempo (sobretudo o tempo escolar) e não pagam IPTU. Qual é a retribuição que oferecem? Não está aí uma boa pista para as escolas? 
Esta reflexão pode soar como quimérica. Antes de alguém firmar esse raciocínio, seria interessante entender como algumas escolas do Piauí e Ceará estão entre as melhores do país e certamente usam o conceito aqui exposto.

Pode-se concluir, afirmando, desta feita sem medo de errar, que essa reflexão só é quimérica porque o discurso dos políticos a favor da escola é demagógico. Brizola, mais do que criador dos CIEPs, criou uma fábrica de CIEPs. Moreira Franco, que o substituiu, apenas disse que o Brasil não tinha dinheiro para essa escola e encerrou o programa.

\section{RELAÇÕES ENTRE TURISMO E LAZER: O CASO DO TURISMO SEXUAL}

As relações entre lazer e turismo são mais estudadas. Sabe-se, por exemplo como lembra Pronovost (2018), que as ciências sociais do turismo, no seu início, importaram as principais categorias de análise do lazer. Para Marc Boyer (1972), o turismo nada mais é que lazer praticado fora da cidade onde se mora. Para MacCannel (1976), o turismo é campo de estudo de uma nova teoria de classe do lazer, reproduzindo o título da obra clássica de Veblen, uma das primeiras abordagens sociológicas do lazer contemporâneo. Como lembra o próprio Pronovost, as ciências sociais do turismo se distanciaram do lazer quando assumiram sua principal característica, a de representar para o turista uma tripla mudança: de paisagem, de ritmo e de estilo de vida.

Mas o lazer praticado com essa tripla mudança é o mesmo lazer que o indivíduo pratica em sua casa e na mesma cidade? Do ponto de vista empírico, já se notou à exaustão que o turismo, embora às vezes ainda praticado por motivos utilitários (profissionais, familiares, religiosos, de saúde), traduz-se numa viagem que traz embutido algum projeto de lazer e a maior parte delas são de lazer tout-court. Em outras palavras: o turismo não é a única atividade "nobre" de lazer, mas é a mais "distinta" - seja no sentido valorativamente positivo de refinamento, de desejo genuíno de apreciar novas sociedades e novas paisagens, seja no sentido negativo, que lhe atribui Pierre Bourdieu (2007), de mera ostentação, que Ihe atribui Pierre Bourdieu (2007). Viajar é o projeto mais citado por ganhadores de loterias, é o primeiro impulso de quem recebeu alguma bolada e, principalmente, é a pergunta que mais pressiona os indivíduos em ascensão socioeconômica e o prazer do lazer é o mais buscado em viagem, mesmo de negócios e exceto quando, no turismo de saúde, somos o paciente e mesmo assim se incomodados com dores.

Explica-se assim a obsessão dos indivíduos em tentar às vezes simplesmente tomar ambos os termos como sinônimos ou reduzir um ao outro. Contudo, mais importante do que as diferenças, falemos da principal semelhança: ambos têm na ludicidade ou, mais precisamente, no prazer que proporcionam o seu principal foco. E como o turismo requer um investimento adicional, é natural que dele se cobre resultado lúdico ainda maior do que o lazer cotidiano. Aceita-se que o trabalho não seja uma fonte de prazer, aceita-se que a vida em família nem sempre seja um mar de rosas, mas a ausência de retorno lúdico de uma atividade de lazer ou de uma viagem traduz-se nas palavras de tantos como "dinheiro jogado fora". Por isso, fala-se mais em turismo de experiência do que de lazer de experiência, mas, na verdade, é em ambos que o retorno lúdico é mais esperado.

De qualquer forma, o que se quer acentuar aqui é a motivação lúdica, de prazer, presente no turismo. E quando se fala em ludicidade, há que se lembrar as duas atividades mais prazerosas dos indivíduos, conforme o criador da neuroendocrinologia Jean-Didier Vincent (2000). Falo da alimentação e do sexo. Ambas não são atividades de lazer em si mesmas mas, exatamente pelo fato de o lazer e o lazer turístico serem os mais apropriados para a busca do prazer, fazem parte da expectativa dos indivíduos nesses tempos. A explicação está mais na biologia do que na cultura. São atividades essenciais à perpetuação da espécie e, se não fossem prazerosas, as espécies em geral, e a humana em especial, estariam fadadas à extinção.

Coincidentemente, as formas de prazer, mais do sexo até do que da alimentação, são também alvo da distinção entre o "sadio" e o "nocivo". Por serem tão prazerosas, também, são as que mais predispõem os indivíduos à adicção, ao vício, com todas as decorrências possíveis, entre as quais, o impacto negativo no trabalho, na própria saúde ou no equilíbrio familiar, quando se tornam doenças e é desnecessário falar-se aqui de todo o universo de mazelas que acompanham os vícios nessas atividades. 
Sobre a importância da alimentação haveria muito o que se falar. Mas aqui ficaremos na busca do sexo, dentro do conjunto de necessidades humanas, no lazer e no turismo.

Em seu romance Plataforma, Michel Houallebecq (2002) narra na primeira pessoa o caso de um funcionário do Ministério da Cultura francês viciado em turismo sexual e que se torna consultor de uma rede de resorts com o seguinte bordão: o sexo ou qualquer forma de intercurso romântico é a expectativa clara ou oculta de qualquer viagem. Abandone-se o toda viagem, já que tudo, todo, nada, ninguém são termos que não cabem na ciência. É de se imaginar que Madre Tereza de Calcutá fizesse suas viagens sem essa expectativa, por exemplo. Mas é difícil negar a existência desta motivação clara ou oculta na viagem de tantas pessoas.

Antes de continuar, contudo, cabe um parêntese: nenhuma ciência chega à certeza, apenas a uma probabilidade. Todas elas se situam portanto num universo de ambiguidade e que permitem uma refutação. Aliás, como disse Karl Popper (1975), toda teoria proposta deve ser atacada de todos os lados, buscando-se sempre encontrar o plano ou situação ou caso em que ela não se mostre verdadeira. Tudo isso é verdade, mas importa lembrar, com o já citado Jean-Didier Vincent (2000) que a relatividade da ciência nunca é tão evidente como quando se analisa o prazer humano. 0 prazer coloca um problema ontológico que toca as próprias raízes do pesquisador. A discussão sobre o lazer é um exemplo. Um exemplo mais recente ainda é o da liberação das drogas. Aí o pensamento parece perder sua função criativa e desaparece sob a cortina do pré-conceito ou, pior, do preconceito. 0 raciocínio torna-se uma conta de chegada, mera ginástica na direção da própria axiologia, de confirmar aquilo que de antemão se quer confirmado.

Entende-se aí, também, porque o sexo ainda é tabu no turismo e na hotelaria. Não se trata aqui de endossar as conclusões de Houallebecq. Afinal, a atmosfera de moralismo ainda dominante não permite que se veja o dia em que hotéis e prostíbulos vão funcionar juntos. Mas não resta dúvida de que a prática hoteleira dominante ainda está longe de acomodar-se à ideia de que muitos hóspedes têm essa expectativa e gostariam de algum tipo de apoio ou, pelo menos, de não serem boicotados em suas expectativas.

Essa ideologia (é uma ideologia na medida em que orienta protocolos, em que se afirma um valor) contamina não apenas recepcionistas e concierges de hotéis, como a própria noção de turismo sexual, colocada que está no index do turismo. Essa condenação do turismo sexual acaba por englobar tudo o que diz respeito a sexo: não apenas a odiosa e nunca suficientemente combatida exploração sexual de crianças e adolescentes, como o legítimo (embora moralmente contestado nas doutrinas religiosas) desejo do viajante de aproveitar sua liberdade para exercício do sexo e mesmo a ideia até certo ponto jocosa (mas certamente cínica) de que todo turista interessado em sexo que nos visita, seja homem ou mulher, é um saqueador dos nossos recursos naturais. Para o senso comum, hoje, toda forma de sexo no turismo é turismo sexual.

Aliás, repita-se: seria bom que o verdadeiro alvo de todas as políticas de turismo sexual se concentrasse na repressão à exploração de crianças e adolescentes. Mas, para tanto, a força dissuasiva e repressiva do Estado não basta. Uma grande ajuda poderia vir do próprio terreno da prostituição.

Ainda que se entre no pantanoso terreno das liberdades individuais (das drogas, do jogo de azar, do sexo), é bom lembrar que as legislações não criminalizam a prática da prostituição em si, apenas a sua exploração comercial. Mas uma prostituição organizada e constituída dentro dos padrões profissionais necessários, além de representar uma segurança adicional ao turista interessado, poderia gerar uma proteção adicional às crianças e adolescentes. Estas naturalmente seriam proibidas de participar da atividade e as próprias prostitutas teriam interesse em defender seu mercado.

Essa substrato ideológico do turismo sexual tende a se tornar anacrônico diante das infinidades de situações em que o sexo transgride a moralidade e coloca as pessoas numa zona cinzenta entre o sexo convencionalmente aceito e a prostituição. Essa evidência deve aos poucos influenciar as praxes hoteleiras.

\section{CONSIDERAÇÕES FINAIS}

As relações entre hospitalidade, lazer e turismo devem ser enriquecidas em breve com a evolução de pesquisas em torno de um novo conceito, o de mobilidade. A hipermobilidade contemporânea, concebida, segundo Medeiros, Telles e Allis (2018), como um fenômeno com efeitos variados e implicações nos campos 
ambientais, fisiológicos, psicológicos, emocionais, atitudinais, identitários, sociais deve provocar um rearranjo nas bases atuais dessas disciplinas.

Como diz Jean Viard (2005), evoluímos de uma sociedade dominantemente sedentária - Léroi-Gouran (s/d) diria sedentarizada no neolítico e sobressedentarizada na Revolução Industrial - para uma sociedade em mobilidade crescente. Ele lembra que, na França, há algumas décadas, os indivíduos deslocavam-se diariamente em média 5 km. Hoje são 30. A partir dos anos 1950, as viagens começaram a fazer parte do rol de expectativas dos indivíduos. Hoje já se fala em necessidade tanto para o estudante como para o profissional. Hoje, por força das vantagens psicológicas e educacionais das viagens pode-se falar hoje em "direito à viagem", como já se fala em direito ao lazer.

A mobilidade tende, assim, a se transformar assim num paradigma e traz o conceito de hospitalidade para o centro das políticas públicas. Receber e ser recebido passam a ser competências essenciais em tempos de mobilidade. Aliás, pode-se falar que mesmo hoje o conceito de hospitalidade já pode ser considerado central nas políticas públicas, cujo sentido republicano é exatamente o de eliminar ou minimizar mecanismos de exclusão.

Por ora o tema da mobilidade, tal como o da hospitalidade, concentra-se nas migrações (mais recentemente dos refugiados) e no turismo. Mas, se considerarmos a mobilidade um novo paradigma de análise, cabe ir além e pensar em todos os seus desdobramentos nos diferentes planos. Por exemplo, a noção de vizinhança deixa de indicar os indivíduos que moram ao lado. A mudança de domicílio é cada vez mais frequente e às vezes nem temos tempo de conhece-los, quanto mais de interagir com eles. Os vizinhos hoje são os que nos são próximos no trabalho, no lazer e nas relações mesmo que rápidas que estabelecemos nas viagens, nos hotéis.

A mobilidade pode tornar-se tema relevante em todas as disciplinas sociais e humanas e mesmo da saúde. Se já há quem pense nas transformações psicológicas ao longo de uma viagem, como Sheller e Urry (2006), por que não pensar nos desdobramentos da mobilidade no plano físico e biológico? A área de turismo e saúde hoje concentra-se nos controles sanitários de viajantes, como se vacinas e quarentenas fossem o problema central decorrente da mobilidade. A hipótese mais rica parece ser a que busca desvelar todas as mudanças que afetam o indivíduo em mobilidade. Quanto mais nos afastamos de casa, mais dependemos da hospitalidade alheia, mais recursos de sobrevivência devemos carregar, sem falar nas consequências de saúde em geral (estresse, problemas gástricos, emocionais, etc.).

Deve também trazer à tona uma das bases teóricas da hospitalidade, que é a distinção do indivíduo em casa e fora de casa. Em casa, somos nós mesmos. Fora de casa, somos atores, representamos papéis. A imagem do indivíduo que ao chegar em casa à noite, fecha a porta e começa a se desfazer de objetos e roupas que o acompanharam fora de casa pode ser o símbolo de uma cena de restauração da própria identidade.

Afeta ainda a relação entre turismo e lazer. Para o senso comum e estudantes mais apressados, lazer é a prática lúdica dentro da própria cidade, enquanto turismo é o lazer praticado em outras cidades, regiões e países. Mas o paradigma da mobilidade mostra que a verdadeira distinção a ser estabelecida não é entre o lazer praticado na própria cidade e em outra cidade. É entre o lazer em casa e fora de casa (ou da cidade). Como já se mostrou acima, a maior parte do tempo de lazer é vivenciada dentro da própria casa. Assim, o lazer urbano extradoméstico e o próprio turismo podem passar a ser entendidos como o conjunto de mudanças que se operam nos indivíduos dentro de uma nova medida - o quanto ele se afasta de casa.

Além da mobilidade, outros temas também devem passar a frequentar as pesquisas de lazer, turismo e hospitalidade. Se a busca do prazer é uma lógica destas áreas, por que não ir além e estudar a própria felicidade, como já o tentou Mihaly Csikszentmihalyi (1992) e sua teoria sobre o fluir. A economia do turismo tem essa dívida com a área. Não basta estudar as relações entre a viagem e a economia dos países. Há que se pensar um dia em estudar as relações entre dinheiro, consumo e satisfação pessoal, uma espécie de estudo de custo/benefício do turismo, devendo englobar os estudos sobre a economia não-monetizada, da 
qual já fala Sahlins (1979) e que tanto motivou a pesquisa de Pierre Bourdieu, bem como os novos estudos sobre a felicidade humana.

Não resta dúvida também de que esses novos estudos devem operar na esfera interdisciplinar, metodologia da qual muito se fala mas pouco se pratica. Até hoje limitamo-nos à multidisciplinaridade, em que ouvimos respeitosamente nossos colegas de outras disciplinas e, em seguida, falamos simplesmente do ponto de vista de nossa disciplina. Espera-se o dia em que sociólogos, antropólogos, geógrafos, historiadores, psicólogos, economistas e mesmo pesquisadores das áreas de ciências exatas sejam capazes de rediscutir e reformular a própria pesquisa em função da contribuição dos demais.

\section{REFERÊNCIAS}

Augé, M. (1994). Não-Lugares: introdução a uma antropologia da supermodernidade. São Paulo: Papirus, 1994

Bachelard, G. (1996). A formação do espírito científico: contribuição para uma psicanálise do conhecimento. Rio: Contraponto.

Bastos, S. R. (2004). Hospitalidade e história: imigrantes na cidade de São Paulo do século XIX. Cadernos CERU (USP), 15, 151 - 164.

Boorstin, D. (1964) The image: a guide to pseudo-events in America. Nova lorque: Harper and Row.

Bourdieu, P. (2007). A distinção: crítica social do julgamento. São. Paulo: Edusp; Porto Alegre, RS: Zouk.

Boyer, M. (1972). Le tourisme, Paris, Seuil.

Buber, M. (2001). Eu e Tu. São Paulo: Centauro.

Cândido, A. (1964). Os parceiros do Rio Bonito. Rio: José Olímpio.

CEPAL (1963). El desarrollo de America Latina en la post-Guerra.

Charlot, B. (1999). Le rapport au savoir en milieu populaire. Une recherche dans les lycées professionnels de banlieue. Paris, Anthropos

Csikszentmihalyi, M. (1992). A psicologia da felicidade. São Paulo: Saraiva

Dufourmantelle, A. (2003). Anne Dufourmantelle convida Jacques Derrida a falar da Hospitalidade. São Paulo: Escuta.

Flusser, V. (1998). A fenomenologia do brasileiro. Rio: UERJ.

Foucault, M. (1999). As palavras e as coisas: uma arqueologia das ciências humanas. São Paulo: Martins Fontes

Goodwin, H. (2017). The challenge of overtourism. Responsible Tourism Partnership, Working Paper 4, October 2017.

Gotman, A. (2009). O comércio da hospitalidade é possível? Revista Hospitalidade, 6(2).

Holanda, S. B. de (1989). Raízes do Brasil. Rio: José Olympio.

Houallebecq, M. (2002). Plataforma. Rio: Record.

Krippendorf, J. (1989). Sociologia do turismo para uma nova compreensão do lazer e das viagens. Rio: Civilização Brasileira.

Lashley, C. \& Morrison, A. (2005). Em busca da hospitalidade: perspectivas para um mundo globalizado. São Paulo: Manole.

Lévinas, E. (1988). Ética e infinito. Diálogos com Philippe Nemo. Lisboa: Edições 70.

Léroi-Gourhan, A. (s/d). O gesto e a palavra. 2 vols. Lisboa, Ed.70.

Lugosi, P. \& Allis, T. (2019). Migrant entrepreneurship, value-creation practices and urban transformation in São Paulo, Brazil. Revista Brasileira de Pesquisa em Turismo, 13(1), p. 141-163. DOI: http://dx.doi.org/10.7784/rbtur.v13i1.1538

Maffesoli, M. (2005). À sombra de Dioniso. Porto Alegre: Zouk. 
MacCannell, D. (1976). The Tourist. A New Theory of the Leisure Class. Nova lorque, Schocken Books.

Medeiros, B.; Telles, V. \& Allis, T. (2018). Apresentação: Por uma teoria social on the move. Tempo social, 30(2), p. 1-16. DOI: https://doi.org/10.11606/0103-2070.ts.2018.142654

Medina, C. A. (1976). O fim de semana da população do Estado da Guanabara. Centro Latino-Americano de Pesquisa em Ciências Sociais-CELAPES

Miguel, L. F. (2016). Da "doutrinação marxista" à "ideologia de gênero. Revista Direito e Práxis, 7(15), 590621. DOI: https://doi.org/10.12957/dep.2016.25163

Montandon, A. (Org.) (2011). O livro da hospitalidade. São Paulo: SENAC.

Panosso Netto, A. \& Trigo, L. G. G (2009). Cenários do turismo brasileiro. São Paulo: Aleph.

Popper, K. (1975). Conhecimento objetivo: uma abordagem evolucionária. Belo Horizonte: Itatiaia.

Pronovost, G. (2018). A construção da noção de " turista " nas ciências sociais. Revista Hospitalidade. 15(2), 158-168. DOI: https://doi.org/10.21714/2179-9164.2018v15n2.009

Sahlins, M. (1979). Cultura e razão prática. Rio de Janeiro: Zahar.

Santos, M. M. C. \& Perazzolo, O. A. (2012). Hospitalidade numa perspectiva coletiva: O corpo coletivo acoInedor. Revista Brasileira de Pesquisa em Turismo. São Paulo, 6(1), pp. 3-15. DOI: https://doi.org/10.7784/rbtur.v6i1.484

Sheller, M. \& Urry, J. (2006) The new mobilities paradigm. Environment and Planning A, 38(2), 207-26. DOI: https://doi.org/10.1068\%2Fa37268

Shérer, R. (2004). Hospitalités, Paris: Anthropos.

Smith, V. (1977). Hosts and Guests: The Anthropology of Tourism. Oxford Basil Blackwell.

Souza, A. de (1976). As 24 horas do dia do carioca. Rio: IUPERJ

Viard, J. (2005). Court traité sur les vacances, les voyages et l'hospitalité des lieux. Paris: Editions de I’Aube.

Vincent, J.-D. (2000). Biologia das paixões. Lisboa: Europa-Americana.

World Tourism Organization; Centre of Expertise Leisure, Tourism \& Hospitality; NHTV Breda University of Applied Sciences; and NHL Stenden University of Applied Sciences (eds., 2019), 'Overtourism'? - Understanding and Managing Urban Tourism Growth beyond Perceptions, Volume 2: Case Studies, UNWTO, Madrid, DOI: https://doi.org/10.18111/9789284420629

\section{Informações do autor}

\section{Luiz Octávio de Lima Camargo}

Livre-Docente pela Escola de Artes, Ciências e Humanidades da Universidade de São Paulo (EACH-USP). Doutor em Sciences de I`Education pela Univ.Sorbonne-Paris V (Rene Descartes) (1982), título revalidado pela FE-USP como Filosofia e História da Educação.

E-mail: loctavio@usp.br

ORCID: http://orcid.org/0000-0003-4653-1395 